\title{
Benthic foraminiferids as pollution indicators in Southampton Water, southern England, U.K.
}

\author{
A.R. SHARIFI, I.W. CROUDACE and R.L. AUSTIN \\ Department of Geology, The University, Southampton SO9 5NH, U.K.
}

\begin{abstract}
A study of heavy metals in estuarine sediments and foraminiferal tests along with foraminiferal distributions from Southampton Water indicates that:

a) heavy metals have a marked effect upon foraminiferid distribution. Some species are able to tolerate pollution and their relative abundance increases at discharge points, whereas other species develop test deformities. Investigation of cores show that no deformed specimens exist within sediments prior to the introduction of pollution.

b) deformed specimens contain higher levels of elements such as $\mathrm{Cu}$ and $\mathrm{Zn}$ than non-deformed specimens. This indicates that heavy metals may be responsible for the abnormalities within foraminiferid tests. Culture experiments support this hypothesis. Specimens of Ammonia beccarii (Linné) developed abnormal chambers over a period of 12 weeks within a culture medium containing $10-20 \mathrm{ppb}$ of $\mathrm{Cu}$.
\end{abstract}

\section{INTRODUCTION}

Polluted environments and their effect upon foraminiferids have been studied by many investigators from different parts of the world over the last three decades (see for example: Watkins 1961; Bandy et al. 1964a, 1964b, 1965a, 1965b; Schafer 1970, 1973; Schafer \& Cole 1974; Seiglie 1971, 1975; Setty 1976, 1982; Setty \& Nigam 1984; Ellison et al. 1986; Alve 1991). The conclusions drawn from previous investigations are that a) foraminiferid species are sensitive to pollution, b) certain species appear to tolerate pollution and become dominant in contaminated areas, $\mathbf{c})$ certain species develop test deformities in polluted areas. Almost all the previous investigations were based on one sample collection and those who reported deformed specimens within their sample have not attempted to analyse them to establish the presence or absence of particular pollutants. The lack of this vital information (test analysis) may be partly due to the scarcity of a suitably sensitive analytical instrument and to the time consuming sample preparation.

Southampton Water, a typical plain estuary (Dyer, 1973), is an approximately rectangular body of water about $10 \mathrm{~km}$ long and $2 \mathrm{~km}$ wide which forms a north-westerly extension of the central Solent Estuarine System in southern England (see Fig.1). This estuary receives sea water from the English Channel, and also the discharges from a number of rivers and streams, as well as sewage and industrial effluent. Numerous industries are located along its southwestern bank; amongst them is the Esso oil refinery at Fawley, the largest in Britain and one of the most complex refineries in Europe (Knap, 1979; Esso Exxon Chemical, 1987). The refinery is known to be a contributor of metals and hydrocarbons into Southampton Water (Knap, 1979; Armannsson et al. 1985). Williams (1976) estimated a total yearly input of 13,500 tonnes of organic carbon into Southampton Water originating as effluent from the major industries of the area. Of this $80 \%$ came from the refinery, the remaining organic matter being derived largely from the satellite industries of the refinery. At about that time the refinery used about 450 million litres of sea water daily for cooling and discharged about 10-15 tonnes of hydrocarbons into the region (Knap, 1979). Amongst the heavy metals, copper is the most significant; copper chloride is used by the refinery as a sweetening agent and acts as a catalyst in conversion of mercaptans to disulphides (Armannsson et al. 1985). Other local sources of heavy metal input are electricity power stations and other local industries along with contamination by large tankers and ships.

Research, which has been in progress for 4 years. is now able to demonstrate how foraminiferids respond to heavy metal pollution within this region. Nine sites within this estuary have been under investigation (see Fig. 1 for sampling locations). Over 250 grab samples have been collected over a period of 18 months (May, 1987 to August, 1988). The top centimetre of each grab has been sampled for investigation of sediment chemistry. foraminiferid distribution and foraminiferid test analysis. Parameters such as salinity, temperature, $\mathrm{pH}$, dissolved oxygen of sea water just above the sediments and water depth were noted at each of the sampling sites during the course of the study. Salinity within the study area shows little seasonal variation ranging from $25 \%$ o to $33.2 \%$ while the $\mathrm{pH}$ ranges from 7.4 to 8.3 . Dissolved oxygen ranges from $5.5 \mathrm{ml} / 1$ to $11.3 \mathrm{ml} / 1$ whereas the temperature varies from $6.5^{\circ} \mathrm{C}$ to $17.9^{\circ} \mathrm{C}$. The maximum recorded water depth was 9 metres and the minimum 3 metres. These measurements are 


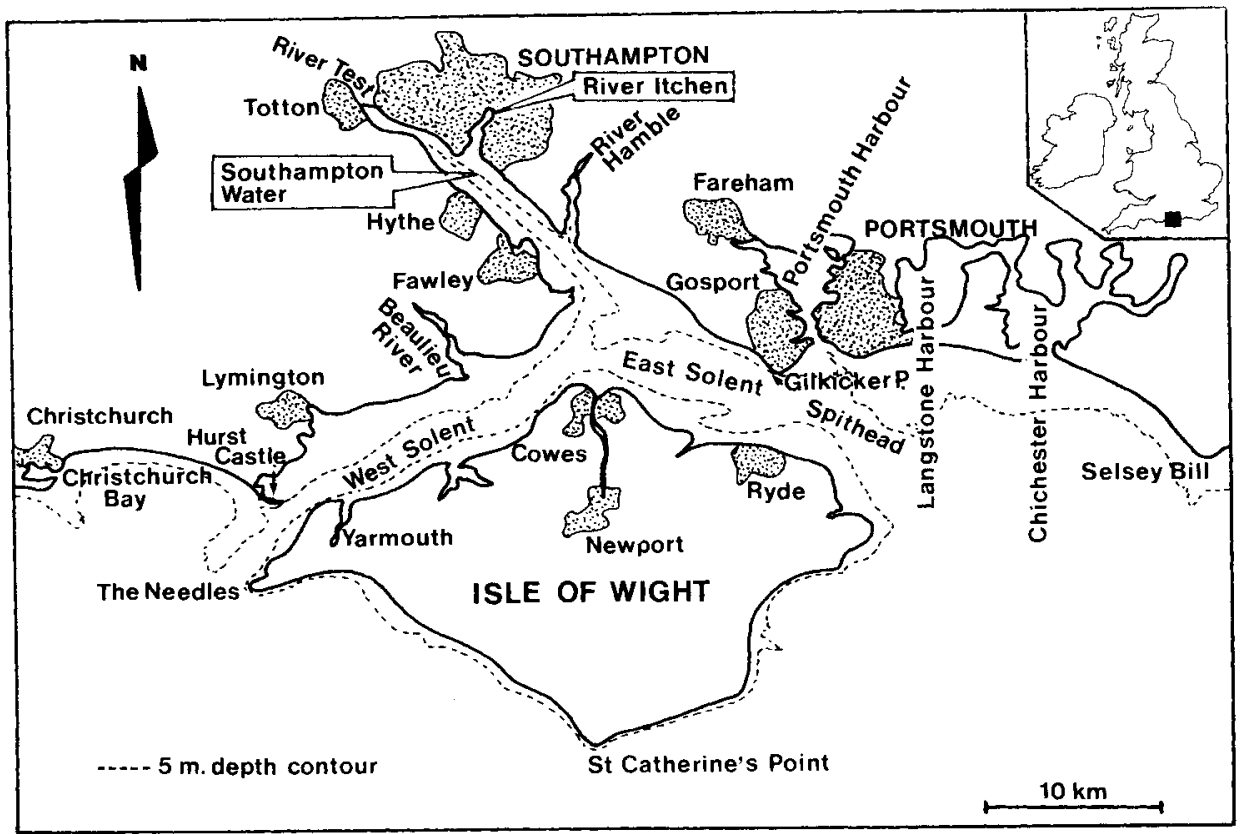

Fig 1: Location of Southampton Water in the Solent, southern England.

not representative of the depth within the entire region, since the main channel of Southampton Water has been dredged to a much greater depth in order to facilitate the movement of commercial shipping.

\section{Sediments:}

The concentrations of seven elements $\mathrm{Cu}, \mathrm{Cr}, \mathrm{Ni}, \mathrm{Zn}, \mathrm{Co}, \mathrm{Cd}$ and $\mathrm{Pb}$ have been determined following a nitric acid leach of the sediments using atomic absorption spectrophotometry (AAS). The maximum observed concentrations of these metals at different sites are illustrated in Table 1.

Based on heavy metal concentrations within sediments the nine sites were categorised into four groups; clean (site 8), relatively clean (sites 1, 3 and 7), relatively polluted (sites 2, 5 and 6) and more polluted (sites 4 and 9 ). The sediments from two sites (sites 4 and 9) reveal relatively high concentrations of all elements compared with the other studied sites. These two sites are fairly close to industrial outfalls indicating that significant discharge of metals is from local industries.

\section{Foraminiferids:}

A total of 67 foraminiferid species have been identified from this estuary of which three living species i.e. Ammonia beccarii (Linné), Haynesina germanica (Ehrenberg) and Elphidium excavatum (Terquem) were observed at all studied sites. The Rose Bengal dye (Walton, 1952) was used to distinguish the dead and living specimens. These three species together constitute over $85 \%$ of the foraminiferid population (living and dead) at all the nine sampled sites. Similarly they constitute over $80 \%$ of the living assemblages at all sites during different times of the year. $E$. excavatum is more dominant than the other two species at sites where sediments contain greater values of metals. Its living percentages are much greater than for other species thus indicating that the species is able to maintain itself despite the presence of heavy metals. The next dominant species after $E$. excavatum at more polluted sites is $H$. germanica. Approximately $5 \%$ of the population of this species show different test deformities. The number of deformed specimens of this species decreases at less polluted sites thus suggesting that it has a limited ability to resist heavy metal pollution. $A$. beccarii shows a different response to pollution, its abundance and living percentage being dramatically reduced at sites where sediments contain greater values for metals. Between $10-20 \%$ of its population were deformed at more polluted sites (sites 4 and 9). The deformed percentage reduced to $5-10 \%$ at less polluted sites (sites 2, 5 and 6). At clean and relatively clean sites both abundance and living percentages increased and no deformed specimens were found.

Foraminiferid abundance and appearance seems to be related to the presence and amount of heavy metals within the local sediments. The abnormalities in the case of $A$. beccarii are in the development of a high spiral side, additional chamber development, twisting of the entire test and sometimes twisting of the last whorl, and twinning. Deformities in $H$. germanica include additional chamber development usually along the last few formed chambers and sometimes an uncoiled extension of the last few chambers. This extension takes place in different directions i.e., perpendicular to the primary plane of growth of specimens, or often parallel to it. In addition to these two species (i.e. A. beccarii and $H$. germanica) deformed specimens of other less abundant species have also been observed, including specimens possessing double apertures. Selective deformed species observed from this region are illustrated in Plate 1.

In the present study test analysis of foraminiferids was carried out using the NERC ICP-MS facility (Inductively Coupled Plasma Mass Spectrometry). The analysis of deformed specimens indicates that they contain much greater values of metals, in particular $\mathrm{Cu}$ and $\mathrm{Zn}$, than non-deformed specimens suggesting 
Benthic foraminiferids as pollution indicators in Southampton Water, southern England, U.K.

\begin{tabular}{|c|c|c|c|c|c|c|c|}
\hline \multirow{2}{*}{ Site } & \multicolumn{7}{|c|}{ Metals in ppm dry weight } \\
\cline { 2 - 9 } & $\mathrm{Cu}$ & $\mathrm{Cr}$ & $\mathrm{Ni}$ & $\mathrm{Zn}$ & $\mathrm{Co}$ & $\mathrm{Cd}$ & $\mathrm{Pb}$ \\
\hline 1 & 51 & 42 & 48 & 143 & 32 & 8 & 81 \\
\hline 2 & 122 & 48 & 58 & 396 & 33 & 9 & 128 \\
\hline 3 & 93 & 41 & 38 & 166 & 26 & 7 & 111 \\
\hline 4 & 1007 & 160 & $\underline{118}$ & $\underline{470}$ & $\underline{71}$ & $\underline{12}$ & $\underline{281}$ \\
\hline 5 & 395 & 88 & 76 & 237 & 52 & 11 & 161 \\
\hline 6 & 109 & 80 & 78 & 216 & 55 & 9 & 161 \\
\hline 7 & 40 & 51 & 36 & 127 & 24 & 10.4 & 75 \\
\hline 8 & 30 & 32 & 21 & 138 & 22 & 73 & 55 \\
\hline 9 & $\underline{641}$ & 130 & $\underline{130}$ & $\underline{403}$ & $\underline{8}$ & $\underline{14}$ & $\underline{23}$ \\
\hline
\end{tabular}

Maximum concentrations of some heavy metals within whole sediments from different sites along Southampton Water.

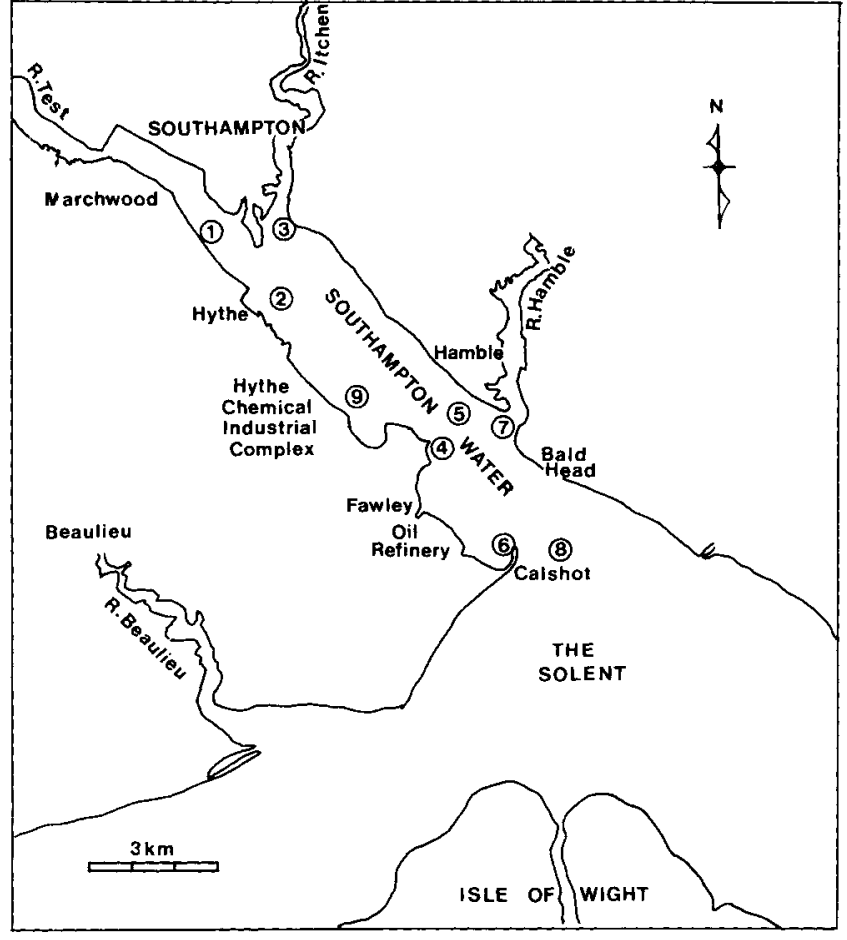

Fig.2. Sampling sites within Southampton Water.

that heavy metals are responsible for the test deformities. Recently Alve (1991) has reported several deformed specimens of different species from Sørfjord in the western part of Norway. Her observations and conclusions were based on two short core samples (maximum $20 \mathrm{~cm}$ long) from this highly metal, polluted fjord. It is interesting to note that the kinds of abnormalities reported by Alve (1991) are very common among deformed specimens observed in Southampton Water, indicating that specimens develop similar test deformities within polluted (heavy metal) environments.

Two gravity core samples were obtained from relatively more polluted sites (sites 4 and 9) in Southampton Water. Unlike
Alve's (1991) core samples which were not long enough to penetrate the entire contaminated zone, the cores collected in the present study were able to reach uncontaminated sediments. Deformed specimens were not found at depths where the sediment contained lesser amounts of metals. This adds strong support to the hypothesis that heavy metals play a role in the development of test deformities in foraminiferids. A. beccarii was more abundant in the region than $E$. excavatum prior to the introduction of industrial effluents, indicating that environmental conditions were favourable for this species. Since the advent of pollutant discharge $A$. beccarii has become less abundant at these localities and higher proportions may be found towards the less polluted central and upper part of the estuary. This suggests that $E$. excavatum has a greater resistance than $A$. beccarii to pollution.

In addition to these field observations a set of culturing experiments has been conducted. Each culturing experiment and its control were carried out for 12 weeks. When the culture medium had 10 and $20 \mathrm{ppb}$ of $\mathrm{Cu}$ specimens of $A$. beccarii produced abnormal chambers, (enlarged chambers) suggesting that the presence of $\mathrm{Cu}$ within the environment may play an important role in the development of test deformities. The result of this aspect of the research will be published in detail elsewhere. However in conclusion it can be inferred with confidence that foraminiferid species can be used as indictors for heavy metal pollution in Southampton Water. E. excavatum appears to be more tolerant to pollution than $A$. beccaril and $H$. germanica The last two species appear to have a limited tolerance in this regard. The degree of tolerance among these species could be ordered as follows: E. excavatum $>H$. germanica $>A$. beccarii.

\section{ACKNOWLEDGEMENTS}

Thanks are due to Professor J.W. Murray for his advice and friendly discussion during the identification and description of non-deformed and deformed specimens. The NERC supported ICP-MS (RHBNC) facility is also gratefully acknowledged. Thanks also to Mr R. Saunders and Mr B. Marsh for their assistance during SEM work and photography.

\section{Manuscript received March 1991 \\ Manuscript accepted May 1991}


A.R. Sharifi, I.W. Croudace and R.L. Austin

\section{REFERENCES}

Armannsson, H. Burton, J.D., Jones, G.B. and Knap. A.H. 1985. Trace Metals and Hydrocarbons in Sediments from the Southampton Water Region, with Particular Reference to the Influence of Oil Refinery effluent: Marine Environmental Research, 15, 31-44.

Alve, E. 1991. Benthic foraminifera in sediment cores reflecting heavy metal pollution in Sørfjord, westem Norway: Journal of Foraminiferal Research, 21(1), 1-19, Pls 1-2.

Bandy, O.L., Ingle, J.C. and Resig, J.M. 1964a. Foraminiferal trends, Laguna Beach outfall area, California: Limnology and Oceanography, 9, 112-123.

Bandy, O.L., Ingle, J.C. and Resig, J.M. 1964b, Foraminifera, Los Angeles County outfall area, Califomia: Limnology and Oceanography,9, 124-137.

Bandy O.L., Ingle, J.C. and Resig, J.M. 1965a. Foraminiferal trends, Hyperion outfall, California: Limnology and Oceanography, 10, 314-332.

Bandy, O.L., Ingle, J.C. and Resig, J.M. 1965b. Modification of foraminiferal distribution by the Orange County Outfall, California: Ocean Science and Ocean Engineering, 55-76.

Dyer, K.R. 1973. Estuaries: A Physical Introduction, Wiley, London, 140pp.

Ellison, R.L., Broom, R. and Ogilvie, R.O. 1986. Foraminiferal Response to Trace Metal contamination in the Patapsco River and Baltimore Harbour, Maryland: Maritime Pollution Bulletin, 17, 419-423.

Esso Exxon Chemical. 1987. Public information brochure, Public Affairs Department, Esso House, London.

Knap, A.H. 1979. The fate of non-volatile petroleum hydrocarbons in refinery effluent entering Southampton Water: Unpublished Ph.D. thesis, Southampton University.

Schafer, C.T. 1970. Studies of benthonic foraminifera in the Restigouche Estuary: 1, Faunal distribution pattern near pollution sources. Maritime sediments 6, 121-

Schafer, C.T. 1973. Distribution of foraminifera near pollution source in Chaleur Bay: Water, Air and Soil Pollution, 2, 219-233.

Schafer, C.T. and Cole, F.E. 1974. Distributions of benthonic foraminifera: their use in delimiting local nearshore environment: Geological Survey of Canada, Paper 74-30, 1,103-108.

Seiglie, G.A. 1971. A preliminary note on the relationships between foraminifers and pollution in two Purerto Rican Bays: Caribbean Journal of Science, 11, 9398

Seiglie, G.A. 1975. Foraminifers of Guayanilla Bay and their use as Environmental Indicators: Revista Española de Micropalentología, 7(3), 453-487.

Setty, M.G.A.P. 1976. The relative sensitivity of benthonic foraminifera in the polluted marine environment of Cola Bay, Goa: Proc. VI Indian Coll Micropaleont. Stratigr. 225-234, Banaras.

Setty, M.G.A.P. 1982. Pollution effects monitoring with foraminifera as indices in the Thana Creek, Bombay area: Inter. Journal Environmental Studies, 18, 205 209.

Setty, M.G.A.P. and Nigam, R. 1984. Benthic foraminifera as pollution indices in the marine environment of the west coast of India: Riv. It. Paleont. Strat. 89 (3), 421 436 .

Walton, W.R. 1952. Techniques for recognition of living foraminifera: Contributions from the Cushman Foundation for Foraminiferal Research, 3 (2), 56-60.

Watkins, J.G. 1961. Foraminiferal ecology around the Orange County, California, ocean Sewer outfall: Micropaleontology, 7, 199-206.

Williams, LeB. P.J. 1976. Organic material in Southampton Water:NERC final report, GR3/1812, 14p.

Plate 1.Some deformed foraminiferid specimens encountered at Southampton Water.

Figs 1-12: Ammonia becrarii (Linné)

1. Spiralside view $x 140$, high-spiral specimen. $2-5$. spiral side views $\times 100,190,120,140$ high spiral specimens showing development of abnormal chambers over the spiral sides, along the last whorls (Figs 2,3) and along the first and second last whorls (figs 4, 5). 6. Oblique view of spiral side $x$ 140, showing development of abnormal chambers, the whorl is bent. 7. Oblique view of spiral side $x 140$, showing development of abnormal chambers along the last whorl, the additional chamber adding in the direction opposite to the original plane of coiling. 8-12. Twin specimens $x 200,110,130,110,160$,twin specimens usually differ in size (one specimen is larger than the other), very rarely twin specimens have an equal size (Fig.10).

Figs 13-18 Havnesina germanica (Ehrenberg)

13. General view $x 90$, last few formed chambers are added in the uncoiled manner. 14. General view $x$ 90, development of abnormal chambers in the same direction as in primary specimens. 15 . General view x 160 , additional abnormal chambers initially are added in the same direction as the primary specimens, while successive chambers are added in a plane perpendicular to the plane of the primary specimen. 16,17. General and oblique views $x 290,240$, last few formed chambers are enlarged, additional chambers are developed along the last few formed chambers of the primary specimens which are perpendicular to the original plane of coiling. 18 . Oblique view x 140 , secondary specimens starting to grow from the last formed chamber of the primary specimens, secondary specimens coiled in a direction opposite to the primary specimen.

Fig. 19 Elphidium magellanicum Heron-Allen and Earland

General view $\times 200$, showing twisting ofthe entire test and development of several abnormal chambers.

Fig. 20 Buliminella gibbalelongata Forasini and d'Orbigny respectively

Generalview x 120, showing two apertures. 


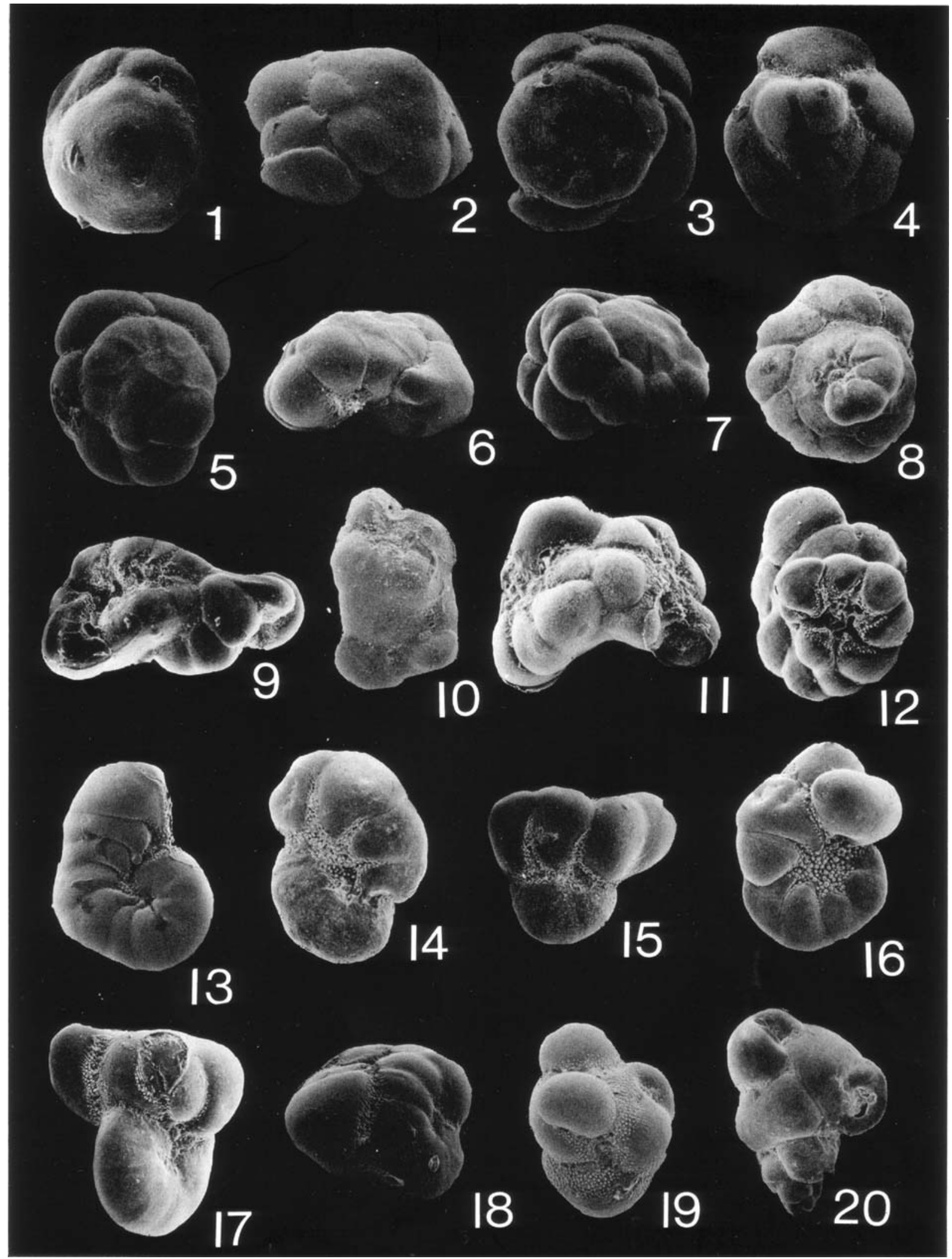

